\title{
Un lienzo inédito de Francisco Barrera (1595-1658): apuntes sobre pintura ridícula en la España del siglo XVII
}

An unpublished canvas by Francisco Barrera (1595-1658): notes for a ridiculous painting in the Spanish 17 th century

\section{Gonzalo Hervás Crespo ${ }^{1}$}

Universidad Complutense, Madrid

Resumen: El presente artículo da a conocer una pintura ridícula de Francisco Barrera, que ayuda a contextualizar otro tipo de obras anónimas de similar factura, y comprender mejor las estrategias comerciales que algunos artistas siguieron en el Madrid de la primera mitad del siglo XVII.

Palabras clave: Francisco Barrera, Pintura de género, Naturaleza muerta, Mercado artístico.

Abstract: This article presents a ridiculous painting by Francisco Barrera, which helps contextualize other anonymous works of similar matter and author, in order to understand with more detail the commercial strategies that some artists followed in Madrid in the first half of the 17 th century.

Keywords: Francisco Barrera, Genre Painting, Still-Life, Art Market.

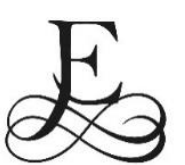

n octubre de 2019 salían al mercado artístico dos lienzos del pintor madrileño Francisco Barrera. El primero, una pintura de género llamada Bodegón con mozo de cocina -aunque preferimos denominarla Interior con figura ridícula- (Fig. 1), se encuentra firmada y fechada en 1633 o 1635; el segundo, también con la firma del pintor y con fecha segura de 1633, presenta una naturaleza muerta sin figuración donde aparecen colgadas diversas piezas de carne. Ambas imáge-

1(b https://orcid.org/0000-0002-4865-8464

(C) 2020 Philostrato. Revista de Historia y Arte 


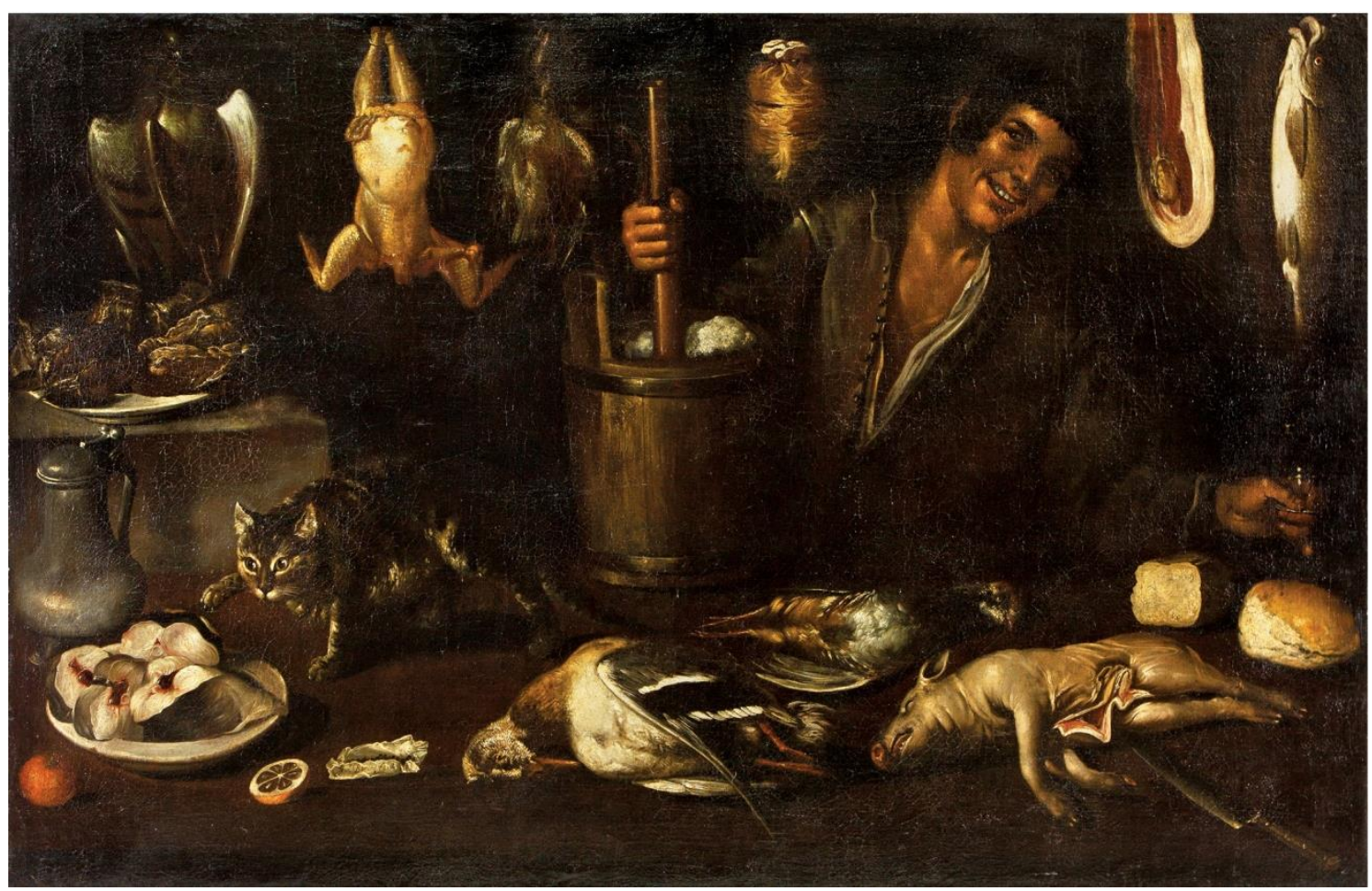

Fig. 1. Francisco Barrera, Interior con figura ridícula, 1633 o 1635, colección privada.

nes suponen las obras autógrafas más tempranas que conocemos del artista². Julio Cavestany aseguraba en 1940 que dos pinturas de Barrera, fechadas en 1635, con "cazas, carnes, longanizas colgadas y otros manjares", se encontraban en la colección del marqués del Sabroso ${ }^{3}$. Sería sugerente pensar que se trata de las mismas que ahora salen a la venta, aunque Cavestany indicaba que una de ellas estaba firmada sobre un limón. En este caso, aunque muy próximo a un limón, la rúbrica se encuentra sobre un canutillo de pimienta.

El primero de los cuadros, además de catalogarlo como una pintura de género podemos asegurar que resulta una pintura ridícula, tal como planteó

\footnotetext{
2 Salvador Salort Pons, "Francisco Barrera. Aproximación a su biografía", Archivo español de arte, 68, 271, (1995), pp. 285-298 y Peter Cherry, Arte y naturaleza. El bodegón español en el Siglo de Oro, (Madrid: Fundación de Apoyo a la Historia del Arte Hispánico, 1999), pp. 200-206., Las dos obras subastadas en Abalarte, Madrid, en octubre de 2019: Francisco Barrera, Interior de cocina, 1633, (óleo sobre lienzo, firmado "fran(co) barera Ft.", $105 \times 164 \mathrm{~cm}$ ). Y Francisco Barrera, Interior con figura ridícula, 1633 o 1635, (óleo sobre lienzo, firmado "fran (co) Barera Ft.", 105 x 164 cm.). (En web: http://abalartesubastas.com/lote elegido nuevo.php?subasta $=31 \&$ numero lote $=108 \& i d=63442 \&$ catego ria $=$ Pintura\&seccion $=$ Pintura + Antigua\&orden=numero lote\&sentido $=\&$ offset $=$ \&limite $=15 \&$ autor $=\&$ vendi do=\&activo=\&idioma=\&tabla $=$, consultada: 25 febrero 2020). Ver también (En web: https://arsmagazine.com/dos-bodegones-ineditos-de-francisco-barrera-en-abalarte/, consultada: 25 febrero 2020).

3 Floreros y bodegones en la pintura española, ed. Julio Cavestany, (Madrid: Palacio de la Biblioteca Nacional, 1940), p. 74.
} 


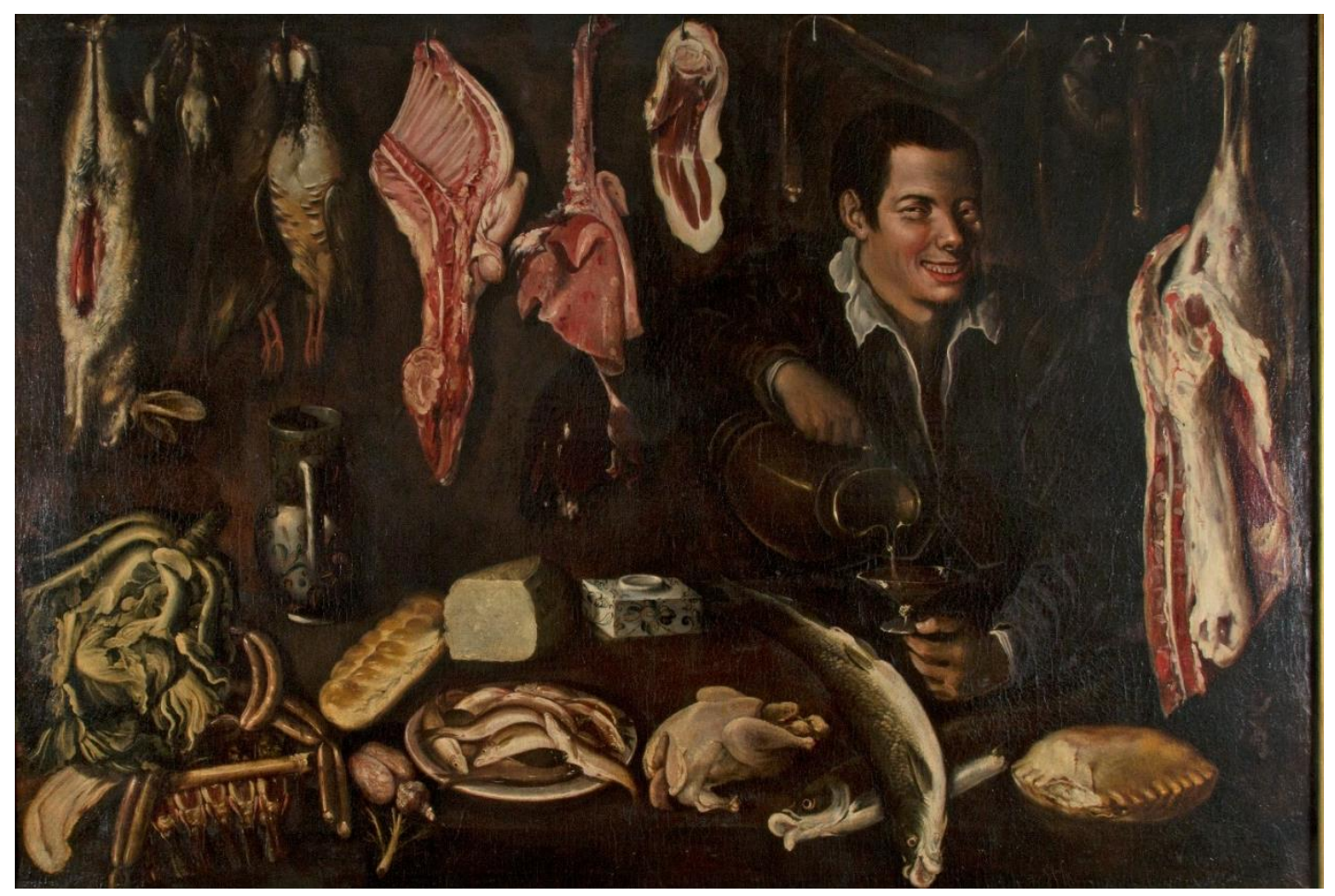

Fig. 2. Anónimo, Interior con figura ridícula, $1^{\mathrm{er}}$ tercio siglo XVII, Madrid, Museo Nacional de Artes Decorativas.

el cardenal Gabriele Paleotti (1522-1597) en 15824. Este concepto, que aglutina una mirada negativa hacia imágenes donde lo cómico se encuentra en el centro del relato, fue recogido en España por los más importantes teóricos de la pintura del siglo XVII, como son Vicente Carducho (1585-1638), Francisco Pacheco (1564-1644), o incluso ya en el XVIII, Antonio Palomino $(1655-1726)^{5}$.

\footnotetext{
4 "Y puesto que de entre las varias formas de las que suele generarse tal recreación, una se causa principalmente por las pinturas que no solo están bellamente hechas, sino que tienen algo más, que excitan el corazón de repente a regocijarse, lo que llamamos ridículo (...) Además de esto debe advertirse que tal divertimento se ha de procurar a través de pinturas honestas, no lascivas o inmodestas, debiendo huir de esto en todas las suertes de recreación, para que de esta manera recreen el ánimo y no lo corrompan, por ello habrá que alejarse más de las pinturas obscenas, que afectan más a los sentidos. Lo mismo opinamos de otras pinturas que representan escenas de gula, embriaguez y vida disoluta si provocan la risa en los espectadores, debiendo siempre advertir que no disminuyan la estimación de las virtudes", Gabriele Paleotti, Discorso intorno alle imagini sacre e profane, en Trattati d'arte del cinquecento: fra manierismo e controriforma: Gilio-Paleotti-Aldovrandi, vol. 2, ed. Paola Barocchi, (Bari: Laterza \& Figli, 1961), pp. 395-396.

${ }^{5}$ Vicente Carducho, Diálogos de la pintura, su defensa, origen, esencia, definición, modos y diferencias, ed. Francisco Calvo Serraller, (Madrid: Turner, 1979), pp. 338-339, Francisco Pacheco, Arte de la pintura, su antigüedad y su grandeza, ed. Bonaventura Bassegoda, (Madrid: Cátedra, 2001), p. 516, y Antonio Palomino, El museo pictórico y escala óptica, volumen III. El parnaso español pintoresco laureado, (Madrid: Imp. por la viuda de Juan García Infanzón, 1724), p. 314. La denominada pintura ridícula, apenas ha dejado eco en la historiografía española contemporánea; después de su mención en los textos de los teóricos precedentes, su incorporación habrá de esperar hasta los años ochenta del pasado siglo, en Jonathan Brown, Velázquez pintor y cortesano, (Madrid: Alianza, 1986), p. 15. Ver también Cherry, Arte y naturaleza, pp. 108-109. La pintura de género española ha sido abordada en Marianna Haraszti-Takács, Spanish Genre Painting in the Sevententh Century, (Budapest: Akadémiai Kiadó, 1983) y Barry Wind, Velázquez's Bodegones: A Study in Seventeenth-century Spanish Genre Painting, (Fairfax, Virginia:
} 
Desde mediados del siglo XVI, imágenes de interiores de cocina o puestos de mercados comenzaron a proliferar en Flandes, convirtiéndose en motivo de gran éxito, con individuos procedentes de las clases populares retratados en sus tareas cotidianas, y mirando de forma directa al espectador ${ }^{6}$. También en Italia surge esta novedad hacia 1580, especialmente en la zona del Milanesado7; se trata de una plástica que se reconfigura de similar manera, pero con el añadido de presentar los personajes una actitud risueña que podríamos definir como de talante burlesco, muy en paralelo a una cultura carnavalesca ${ }^{8}$, y que sin duda ayudó a cimentar la idea de pintura ridícula en Paleotti.

Este tipo de imágenes que exploran lo jocoso de la naturaleza humana, acompañadas de una sugerente dosis de vulgaridad, son aquellas que las autoridades religiosas evaluaron como perjudiciales para los deseos de renovación espiritual y moderación que pretendían a través del Concilio de Trento. Se entiende así que Paleotti, así como otros reformadores, trataran de poner freno tanto a una literatura como a un tipo de registro visual que se deslizaba hacia presupuestos donde la gula y la lujuria ayudaban a construir una narrativa cómica.

Es probablemente esta impugnación de los elementos ridículos y grotescos de raigambre carnavalesca la que ayudó, entre otros motivos, a que la pintura de género apenas tuviera repercusión en la España del siglo XVII ${ }^{9}$. A pesar de ello, existen una serie de obras anónimas con individuos sonrientes que miran al espectador, tradicionalmente fechadas en el primer tercio del siglo $X V I I^{10}$, y que son el resultado de una formulación española de las obras del norte de Italia. En España, la Escena de mercado de Juan Esteban de Úbeda de 1606 puede considerarse como la primera obra de género conocida, y

George Mason University Press, 1987). De gran interés resulta, asimismo, la obra ya mencionada, Cherry, Arte y naturaleza, especialmente en su capítulo tercero.

${ }^{6}$ Una bibliografía general de este tipo de plástica, Keith Moxey, Aertsen, Beuckelaer, and Secular Painting in the Reformation, (New York: Garland, 1977), Reindert Falkenburg, "Pieter Aertsen, Rhyparographer", en Rhetoric-Rétoriqueurs-Rederijkers, eds. Jelle Koopsmans, Mark Meadow, Kees Meerhoff y Marijke Spies, (Amsterdam: North-Holland Publishing Company, 1995), pp. 197-217, y Larry Silver, Peasant Scenes and Landscapes: The Rise of Pictorial Genres in the Antwerp Art Market, (Philadelphia: University of Pennsylvannia Press, 2006), pp. 87-102.

7 Para un somero repaso de la pintura ridícula en el norte de Italia, resulta imprescindible, Barry Wind, "Pitture ridicule: Some Late Cinquecento Comic Genre Paintings", Storia dell'Arte, 20, (1974), pp. 25-35, Francesco Porzio, Pitture ridicule. Scene di genere e tradizione popolare, (Milan: Skira, 2008), Michel Hochmann, "Les portraits de bouffons et la naissance de la peinture comique en Italie du nord au XVIe siècle", Studiolo, 7, (2009), pp. 41-54, Valérie Boudier, La cuisine du peintre. Scène de genre et nourriture au Cinquecento, (Rennes: Presses universitaires, 2010) y Angela Ghirardi, Pittura e vita popolare, (Mantua: Trelune, 2016).

${ }^{8}$ Rabisch. Il grotesco nell'arte del Cinquecento. L'Accademia della Val di Blenio, Lomazzo e l'ambiente milanese, ed. Giulio Bora, Francesco Porzio y Manuela Kahn-Rossi, (Lugano: Museo Cantonale d'Arte, 1998).

${ }^{9}$ Esta es una cuestión que, junto a la fortuna historiográfica y el estudio sistemático de la pintura de género española, hemos abordado en nuestra tesis doctoral recientemente defendida, Figuras ridículas: la pintura de género en España en el siglo XVII, Universidad Complutense. (Madrid: 2019) y que esperamos pueda ver la luz en una próxima publicación.

10 Gonzalo Hervás Crespo, "Bodegones habitados: mercados, cocinas y despensas en la pintura española del siglo XVII", en El Barroco, universo de experiencias, ed. José Antonio Peinado Guzmán y María del Amor Rodríguez Miranda, (Córdoba: Hurtado Izquierdo, 2017), pp. 215-236. 
responde a estos parámetros ${ }^{11}$. El resto de pinturas que abrazan esta tipología ridícula, probablemente estén realizadas en la década de los veinte o principios de los treinta del siglo XVII, en un momento en el que empieza a proliferar la pintura de naturalezas muertas en la corte madrileña ${ }^{12}$. Nos referimos a obras como Cocina con figura ridícula (Fig. 2), del que existen dos copias exactas pero de diferente mano ${ }^{13}$. De igual modo sucede con el denominado El sueño del glotón, que también presenta una réplica hoy en paradero desconocido ${ }^{14}$. Existen, a su vez, otros cuadros de este tipo en colecciones particulares, derivados de los modelos italianos. La aparición de una obra cuya similitud estética es evidente, de mano de un pintor bien documentado en Madrid, ayuda a contextualizar estas imágenes; el que además aparezca la fecha, resulta crucial para certificar que el resto de pinturas se hicieron entre 1620 y 1635.

Centrándonos en la obra de Barrera, conviene mencionar la similitud con obras italianas, como pueden ser las de Jacopo Chimenti o da Empoli (1551$1640)^{15}$. Pero, sobre todo, es imprescindible señalar la importancia de Juan Van der Hamen (1596-1631) en sus esquemas compositivos, pues resulta el gran innovador de la naturaleza muerta en la década de los veinte del siglo XVII ${ }^{16}$. Tomando las pocas imágenes que Juan Sánchez Cotán (1560-1627) había dejado en Toledo ${ }^{17}$, Van der Hamen crea una serie de diseños que resultan un éxito en la corte de Madrid, favoreciendo la aparición de imitadores ${ }^{18}$. En este sentido, son varios los artistas que van a reproducir dichos modelos tras la temprana muerte del artista. Es el caso de Barrera, pues las formas estructurales o plintos que ayudan a componer y distribuir los objetos en la obra que presentamos, son una creación de Van der Hamen de hacia 1626-1627, quizá derivado de fórmulas italianas o imágenes procedentes del clasicismo ${ }^{19}$.

De los abundantes documentos sobre su vida, se puede colegir que Barrera dedicó su arte principalmente a obras devocionales, naturalezas muertas y

\footnotetext{
11 Juan Estéban de Úbeda, Escena de mercado, 1606, (128 x 167 cm.). Granada, Museo de Bellas Artes, (cat. CE0126). Para este pintor, ver Antonio Almagro, "Juan Esteban de Medina y la pintura ubetense del siglo XVII", Boletín del instituto de estudios Giennenses, 209, (2014), pp. 11-67. Juan Esteban se encontraba en Madrid a finales del siglo XVI, donde pudo haber contemplado novedades llegadas a la corte desde Italia, ver Pintura española de bodegones y floreros. De 1600 a Goya, ed. Alfonso Pérez Sánchez, (Madrid: Museo del Prado, Madrid, 1983), p. 71.

12 Hacia 1630, la naturaleza muerta despega masivamente en Madrid, Cherry, Arte y naturaleza, p. 199.

${ }^{13}$ Interior con figura ridícula, (óleo/ lienzo, $110 \times 165 \mathrm{~cm}$.). Madrid, Museo Nacional de Artes Decorativas, (cat. CE26383) y (óleo/ lienzo, 106 x 163,5 cm.). Segovia, Palacio de Riofrío, (cat. 10066508).

${ }^{14}$ El sueño del glotón, (óleo/ lienzo, $138 \times 146 \mathrm{~cm}$.). Museo de Pontevedra, (cat. 004105). Ambas obras, la de Pontevedra y la que continua en paradero desconocido fueron publicadas por Antonio Méndez Casal, "El pintor Alejandro de Loarte", Revista española de arte, (1934), pp. 187-202.

15 William B. Jordan, "Alonso de Escobar (documentado 1602-después de 1637)", Catálogo de subastas Alcalá, mayo 2003, p. 31.

${ }^{16}$ Cherry, Arte y naturaleza, pp. 145-187; Juan Van der Hamen y la corte de Madrid, ed. William B. Jordan, (Madrid, Dallas: Palacio Real, Meadows Museum, 2005).

17 El primer encargo de Van der Hamen se concretó en 1619, para una sobrepuerta de la Galería del Mediodía en el Palacio del Pardo, para que encajase junto a otras cinco pinturas con muchas trazas de ser de Sánchez Cotán, ver La imitación de la naturaleza: los bodegones de Sánchez Cotán, ed. William B. Jordan, (Madrid: Museo del Prado, 1992), pp. 48-50.

${ }^{18}$ Cherry, Arte y naturaleza, p. 199.

${ }^{19}$ Cherry, Arte y naturaleza p. 158; Jordan, Juan Van der Hamen, p. 267.
} 


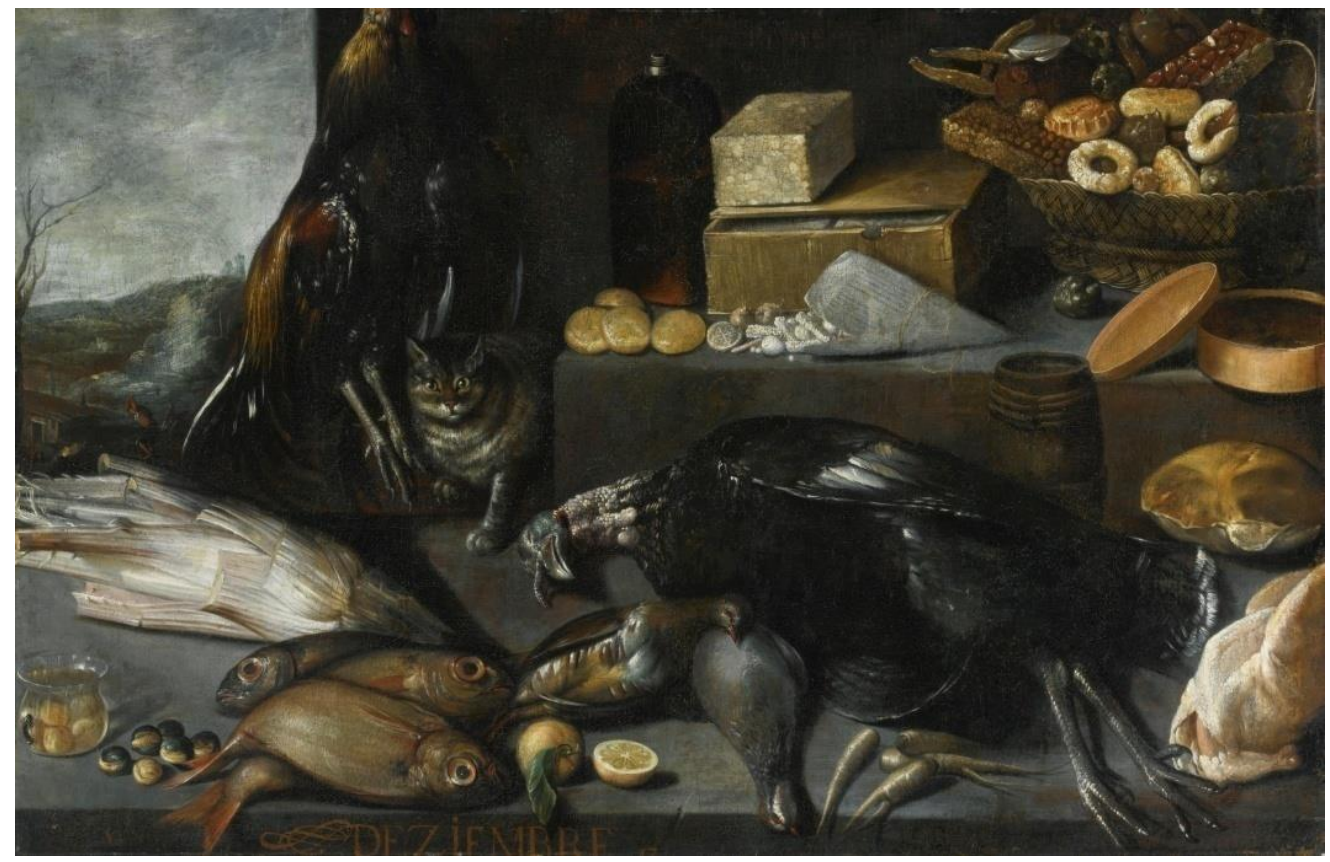

Fig. 3. Francisco Barrera, Mes de diciembre, c.1640, colección privada.

paisajes. Gracias a estos datos podemos considerarlo un pintor comercialmente inquieto, y que hizo una considerable fortuna ${ }^{20}$. Dotado de un agudo sentido comercial, Barrera encontró en la representación de alimentos un asunto propicio del que extraer un buen rendimiento económico. Es aquí quizá donde haya que entender una obra como Interior con figura ridícula. Barrera fue un artista con una gran capacidad para entender cierto mercado de pintura, realizada al por mayor, pues vendió lienzos de forma masiva como indica la alcabala de 1638, donde figura como el pintor más exitoso comercialmente de Madrid en esos años, doblando incluso en ventas al siguiente ${ }^{21}$. Para ello mantuvo tratos con diversos artífices para comprar y vender cuadros en las tiendas que tenía abiertas en Madrid, lo que indica su clara vocación empresarial ${ }^{22}$. Con todos estos datos, queremos señalar que esta obra ridícula probablemente responda a un encargo puntual, y que Barrera prefería dedicarse a naturalezas muertas o paisajes carentes de especial complejidad ${ }^{23}$. En su caso, y conociendo el resto de su catálogo, resultan mucho más interesantes comercialmente las series de los tiempos del año, pues responden a un tema alegórico de cierta entidad que aúna naturaleza muerta y figuración sencilla, existiendo además la posibilidad de multiplicar el número de lienzos.

\footnotetext{
20 Salort, "Francisco Barrera", p. 285 y Cherry, Arte y naturaleza, p. 200.

21 Julián Gállego, El pintor, de artesano a artista, (Granada: Diputación provincial, 1995), pp. 160-161.

22 Cherry, Arte y naturaleza, p. 200.

${ }^{23}$ Cherry, Arte y naturaleza, p. 201.
} 


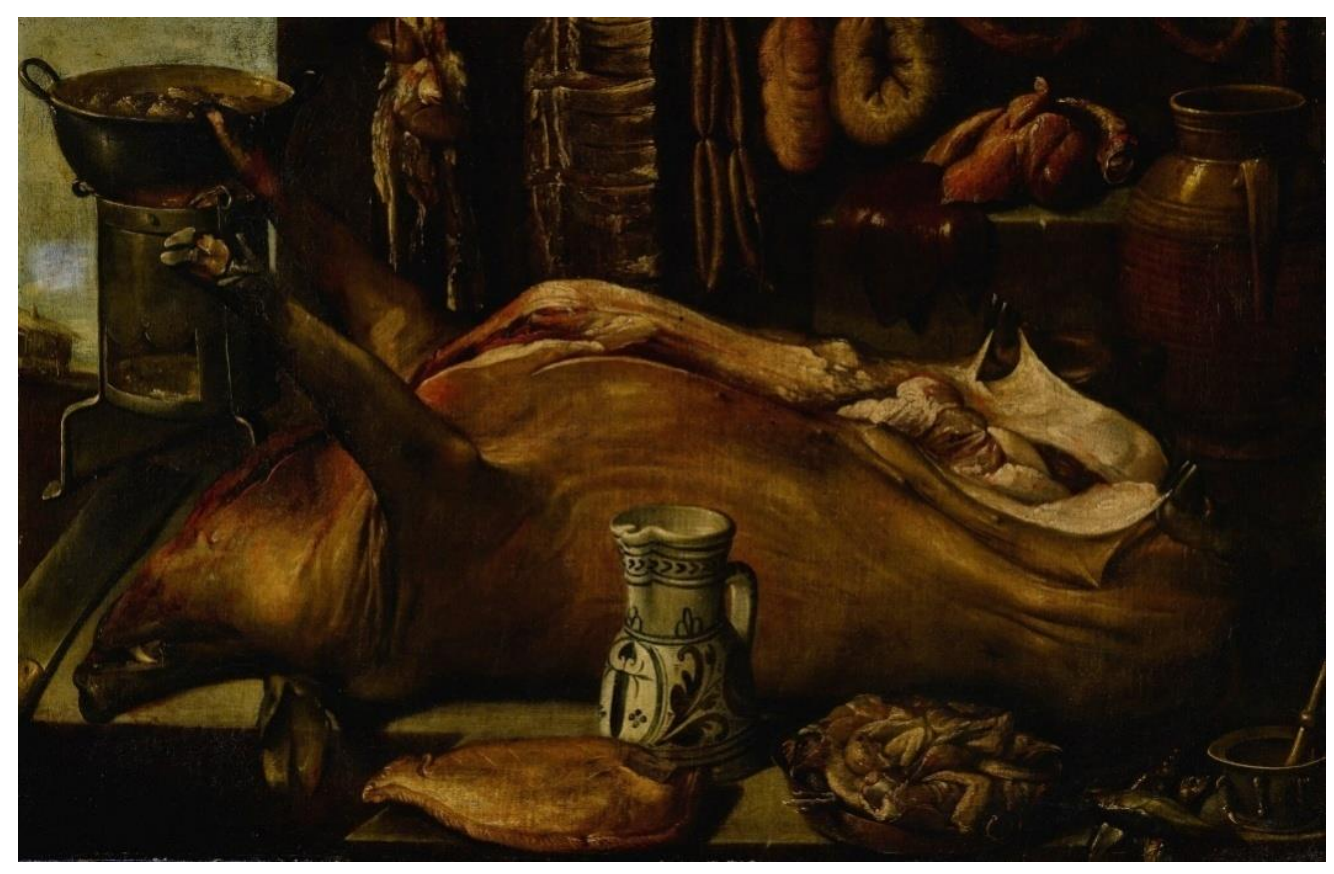

Fig. 4. Francisco Barrera, Mes de enero, c.1640, colección privada.

De este modo, las alegorías de las estaciones de 1638 resultan un buen ejemplo ${ }^{24}$. Pero igualmente diseñó otras relacionadas, como son aquellas que hacen referencia a los meses del año. Se trata de ciclos decorativos que muestran a un artista que entendió a la perfección la demanda de un género nuevo como el de la naturaleza muerta, y la posibilidad de obtener ganancia con ello. En este sentido, cabe destacar la serie de los doce meses, de la que al menos nueve cuadros han llegado a nosotros. Los lienzos estaban en posesión de Vicente Joaquín Ossorio de Moscoso, IX marqués de Leganés, fallecido en 1864, por lo que es plausible pensar que pudiese haber sido encargada por el I marqués, Pedro Mexía Felípez de Guzmán (c. 1580$1655)^{25}$. Aunque el nombre de Barrera no aparezca en los inventarios realizados a la muerte de éste, su presencia en la documentación de su descendiente, y el hecho de que en buena medida la colección se mantuviera en manos de la familia hasta precisamente $1864^{26}$, hacen lícita esta hipótesis.

Es posible reconstruir parte del ciclo con este inventario, pues algunos de los cuadros eran conocidos, y otros que han ido apareciendo en el mercado del arte en los últimos tiempos encajan a la perfección con este documento. En 2014 una obra que representa el mes de marzo, ya publicada por Peter

\footnotetext{
${ }^{24}$ Nos referimos a cuatro óleos conservados en el Museo de Bellas Artes de Sevilla, con medidas idénticas $\left(167 \times 247 \mathrm{~cm}\right.$.). La primavera ( $\mathrm{n}^{\circ}$ cat. DJ0323P), El verano ( $\mathrm{n}^{\circ}$ cat. DJ0324P), El invierno ( $\mathrm{n}^{\circ}$ cat. DJ0325P) y El otoño (no cat. DJ0326P).

25 José Juan Pérez Preciado, El marqués de Leganés y las artes, tesis doctoral inédita, Universidad Complutense, (Madrid: 2010), p. 929.

26 Pérez Preciado, El marqués, p. 904.
} 
Cherry ${ }^{27}$, apareció a la venta en Madrid. Descrita en el inventario como: "Marzo. Un bodegón con pescados coliflor salmon esperragos ${ }^{28 "}$. Un año después, en 2015, dentro del grupo de pinturas donadas por Plácido Arango al Museo del Prado se encontraba el mes de febrero29; en 2016 salía a la venta otro cuadro: "Diciembre. Un bodegón con besugos perdices, pavo, cardo, jalea y rosquillas. Compañero a los anteriores ${ }^{30 "}$. (Fig. 3) En este caso, puede apreciarse como el gato que aparece por detrás de una de las estructuras, es similar al que aparece en el Interior con figura ridícula, indicativo de que quizá Barrera crea una serie de modelos, que luego su taller replica combinando formas y motivos para multiplicar lienzos. Por último, en 2019, una pintura denominada Alegoría del invierno, no es sino el principio de la serie, pues representa el mes de enero, tal y como puede leerse: "Enero. Bodegón que representa un cerdo, despojos y embutidos y una jarra con la cruz de Santiago. Original de Francisco Barrera primero de la colección de los 12 meses del año ${ }^{31 "}$. (Fig. 4) Con el conocimiento de estos últimos lienzos, que coinciden con la documentación expuesta por Pérez Preciado, puede casi completarse a falta de tres cuadros la serie de obras que probablemente el primer marqués de Leganés encargara a Barrera hacia 1640.

Con este artículo se pretende dar a conocer una obra como Interior con figura ridícula, tratando además de contextualizarla a través de la vocación empresarial de un artista como Barrera, lo que también ayuda a comprender parte de las maniobras crematísticas de los artistas en la España del siglo XVII, asunto que pensamos merece seguir investigándose. Resultan muy escasas las obras españolas de este tipo, y casi todas anónimas. En el caso de otras pinturas de Barrera donde aparece figuración humana, caso de las alegorías de las estaciones, nunca presentan una vertiente cómica. Se trata de personajes ocupados en quehaceres estacionales, conformando parte del tiempo que se señala a modo de metáfora visual, sin una verdadera conexión con el espectador.

La aparición de esta obra, netamente ridícula, aporta nuevos datos al contrastarla con las estrategias comerciales de un artista como Barrera, pues podemos especificar a través de su figura la fortuna de este asunto en Madrid. Resulta elocuente que un artista que siempre estuvo al tanto de las

27 Cherry, Arte y naturaleza, p. 201. El mes de marzo, ca. 1640 (óleo/lienzo, $103 \times 160,5$ cm.) Abalarte, Madrid, (octubre de 2014, lot. no 142), (En web: http://abalartesubastas.com/lote elegido nuevo.php?subasta $=5 \&$ numero lote $=142 \&$ id $=6773 \&$ categoria =Pintura\&seccion =Pintura + Antigua\&orden $=$ numero lote\&sentido $=\&$ offset $=\&$ limite $=60 \&$ autor $=$ \&vendido =\&activo=\&tabla=, consultada el 25 de febrero 2020).

${ }_{28}$ Pérez Preciado, El marqués, p. 943.

29 Febrero, Bodegón de invierno, 1640 (óleo/lienzo, $101 \times 156 \mathrm{~cm}$.) Madrid, Museo del Prado, (no inv. P008213).

30 Pérez Preciado, El marqués, p. 904. El mes de diciembre, ca. 1640. Sotheby's, Nueva York, (enero de 2016, lot. no 467), (óleo/lienzo, 101,5 x 156,2 cm.) (En web: http://www.sothebys.com/es/auctions/ecatalogue/2016/master-paintings-sculpture-day-salen09461/lot.467.html, consultada el 25 de febrero 2020).

31 Pérez Preciado, El marqués, p. 943. El mes de enero, vendido en Sotheby's Nueva York (enero de 2019, lot. no 38, c. 1640), (óleo sobre lienzo, 101.6 x 154.9 cm.) (En web: http://www.sothebys.com/en/auctions/ecatalogue/2019/master-paintings-evening-n10007/lot.38.html, consultada: el 25 de febrero 2020). 
posibilidades económicas de la imagen, y que exploró las novedades estéticas llegadas a España, prefiriera la naturaleza muerta con figuración alegórica antes que escenas más vanguardistas. De haber funcionado económicamente, pensamos que Barrera lo habría explotado sin problema.

Para empezar, resultaba un asunto complejo de exhibir públicamente; un pintor como Carducho la condenaba en su influyente tratado ${ }^{32}$, pues en la batalla que algunos artistas libraron para que la pintura fuese considerada un arte liberal, obras señaladas como indecorosas resultaban un potencial peligro para sus intereses. La pintura ridícula fue prohibida en el Concilio de Toledo de $1582^{33}$, aunque esto no impidió que fuera adquirida y coleccionada, por lo que existía una cierta demanda como prueban los cuadros existentes. Pero imágenes como estas resultaban difíciles de colocar fuera del círculo de entendidos que conocían las innovaciones venidas de Flandes o Italia. Además, no parece que las capacidades artísticas de Barrera le hayan alcanzado para desarrollar los modelos conocidos más allá de la mera copia, despertando así el interés de coleccionistas de mayor gusto o sofisticación. A la altura de 1633, las pinturas de cocinas o mercados seguían manteniendo los mismos esquemas compositivos que los del siglo anterior, y los clientes de cierto nivel que deseaban obra de este tipo optaban por adquirir piezas flamencas, de muy superior calidad, aunque resultaban costosas y no siempre disponibles.

Creemos por tanto que pinturas como la de Barrera responden a encargos más económicos, siendo el resultado del deseo de obtener imágenes pintorescas, y que por alguna razón resultan inaccesibles. Se trataría de peticiones a artífices de segunda fila, lo que justifica la escasa calidad de alguna de ellas; o como creemos que sucede en este caso, artistas más o menos conocidos con un interés específico en la naturaleza muerta, y una predisposición a la copia de modelos preexistentes, que pueden ofrecer un producto mucho más asequible, y que finalmente acaba resultando la escueta respuesta española al fenómeno de la pintura de género.

\footnotetext{
32 "Y no tienen poca culpa los artífices que poco han sabido, o poco se han estimado, abatiendo el generoso arte a conceptos humildes, como se ven hoy, de tantos cuadros de bodegones, con bajos y vilísimos pensamientos, y otros de borrachos, otros de fulleros tahúres, y cosas semejantes, sin más ingenio, ni más asunto, de habérsele antojado al pintor retratar cuatro pícaros descompuestos, y dos mujercillas desaliñadas, en mengua del mismo arte, y poca reputación del artífice", Carducho, Diálogos, pp. 338-339. 33 Juan Tejada y Ramiro, Colección de cánones de la Iglesia Española, tomo V, (Madrid: Imp. por Pedro Montero, 1855), p. 435. Esta prohibición no forma parte expresa de los 63 decretos conciliares. A lo largo de las reuniones se trataron diversos temas, entre los que se encuentra la prohibición expresa de la pintura ridícula, que pasaron a una lista denominada "Advertimentos", ver Ángel Fernández Collado, "El Concilio Provincial Toledano de 1582", Anthologica annua, 41, (1994), pp. 103-252.
} 
Bibliografía:

Almagro 2014: Antonio Almagro, "Juan Esteban de Medina y la pintura ubetense del siglo XVII", Boletín del instituto de estudios Giennenses, 209, (2014), pp. 11-67.

Boudier 2010: Valérie Boudier, La cuisine du peintre. Scène de genre et nourriture au Cinquecento, (Rennes: Presses universitaires, 2010).

Carducho 1979: Vicente Carducho, Diálogos de la pintura, su defensa, origen, esencia, definición, modos y diferencias, ed. Francisco Calvo Serraller, (Madrid: Turner,1979).

Cherry 1999: Peter Cherry, Arte y naturaleza. El bodegón español en el Siglo de Oro, (Madrid: Fundación de Apoyo a la Historia del Arte Hispánico, 1999).

Falkenburg 1995: Reindert Falkenburg, "Pieter Aertsen, Rhyparographer", en Rhetoric-Rétoriqueurs-Rederijkers, eds. JelleKoopsmans, Mark Meadow, Kees Meerhoff y Marijke Spies, (Amsterdam: North-Holland Publishing Company, 1995), pp. 197-217.

Fernández Collado 1994: Ángel Fernández Collado, "El Concilio Provincial Toledano de 1582", Anthologica annua, 41, (1994), pp. 103-252.

Gállego 1995: Julián Gállego, El pintor, de artesano a artista, (Granada: Diputación provincial, 1995).

Ghirardi 2016: Angela Ghirardi, Pittura e vita popolare, (Mantua: Trelune, 2016).

Haraszti-Takács 1983: Marianna Haraszti-Takács, Spanish Genre Painting in the Sevententh Century, (Budapest: Akadémiai Kiadó, 1983).

Hervás Crespo 2017: Gonzalo Hervás Crespo, "Bodegones habitados: mercados, cocinas y despensas en la pintura española del siglo XVII", en El Barroco, universo de experiencias, ed. José Antonio Peinado Guzmán y María del Amor Rodríguez Miranda, (Córdoba: Asociación Hurtado Izquierdo, 2017), pp. $215-236$.

Hochmann 2009: Michel Hochmann, "Les portraits de bouffons et la naissance de la peinture comique en Italie du nord au XVIe siècle", Studiolo, 7, (2009), pp. 41-54.

Jordan 2003: William B. Jordan, "Alonso de Escobar (documentado 1602después de 1637)", Catálogo de subastas Alcalá, mayo 2003, pp. 30-37.

Lugano 1998: Rabisch. Il grotesco nell'arte del Cinquecento. L'Accademia della Val di Blenio, Lomazzo e I'ambiente milanese, ed. Giulio Bora, Francesco Porzio y Manuela Kahn-Rossi, (Lugano: Museo Cantonale d'Arte, 1998). 
Madrid 1940: Floreros y bodegones en la pintura española, ed. Julio Cavestany, (Madrid: Palacio de la Biblioteca Nacional, 1940).

Madrid 1983: Pintura española de bodegones y floreros. De 1600 a Goya, ed. Alfonso Pérez Sánchez, (Madrid: Museo del Prado, Madrid, 1983).

Madrid 1992: La imitación de la naturaleza: los bodegones de Sánchez Cotán, ed. William B. Jordan, (Madrid: Museo del Prado, 1992), pp. 48-50.

Madrid, Dallas 2005: Juan Van der Hamen y la corte de Madrid, ed. William B. Jordan, (Madrid, Dallas: Palacio Real, Meadows Museum, 2005).

Méndez Casal 1934: Antonio Méndez Casal, "El pintor Alejandro de Loarte", Revista española de arte, (1934), pp. 187-202.

Moxey 1977: Keith Moxey, Aertsen, Beuckelaer, and Secular Painting in the Reformation, (New York: Garland, 1977).

Pacheco 2001: Francisco Pacheco, Arte de la pintura, su antigüedad y su grandeza, ed. Bonaventura Bassegoda, (Madrid: Cátedra, 2001).

Paleotti 1961: Gabriele Paleotti, "Discorso intorno alle imagini sacre e profane", en Trattati d'arte del cinquecento: fra manierismo e controriforma: Gilio-Paleotti-Aldovrandi, vol. 2, ed. Paola Barocchi, (Bari: Laterza\&Figli, 1961), pp. 390-397.

Palomino 1724: Antonio Palomino, El museo pictórico y escala óptica, volumen III. El parnaso español pintoresco laureado, (Madrid: Imp. por la viuda de Juan García Infanzón, 1724).

Pérez Preciado 2010: José Juan Pérez Preciado, El marqués de Leganés y las artes, tesis doctoral inédita, Universidad Complutense, (Madrid: 2010).

Porzio 2008: Francesco Porzio, Pitture ridicule. Scene di genere e tradizione popolare, (Milan: Skira, 2008).

Salort Pons 1995: Salvador Salort Pons, "Francisco Barrera. Aproximación a su biografía", Archivo español de arte, 68, 271, (1995), pp. 285-298.

Silver 2006: Larry Silver, Peasant Scenes and Landscapes: The Rise of Pictorial Genres in the Antwerp Art Market, (Philadelphia: University of Pennsylvannia Press, 2006).

Tejada y Ramiro 1855: Juan Tejada y Ramiro, Colección de cánones de la Iglesia Española, tomo V, (Madrid: Imp. por Pedro Montero, 1855).

Wind 1974: Barry Wind, "Pitture ridicule: Some Late Cinquecento Comic Genre Paintings", Storia dell'Arte, 20, (1974), pp. 25-35.

Wind 1987: Barry Wind, Velázquez's Bodegones: A Study in Seventeenthcentury Spanish Genre Painting, (Fairfax, Virginia: George Mason University Press, 1987). 
Recibido: 20/03/2020

Aceptado: 4/05/2020 